\title{
Crystal Structure Analysis of (6-hydroxy-8-(2-hydroxyphenyl)- 9-nitro-2, 3, 4, 8-tetrahydro-1H-pyrido [1, 2-a] pyrimidin-7-yl) (1H-indol-3-yl) methanone
}

\author{
K. Hemanathan ${ }^{1}$, R. Raja ${ }^{2}$, J. Kamlraja ${ }^{3}$, K. Sakthi Murugesan ${ }^{1^{*}}$ \\ 1,2Department of Physics, Presidency College (Autonomous), Chennai-600 005, India \\ ${ }^{3}$ Department of Chemistry, Pondicherry University, Pondicherry-605 014, India
}

ABSTRACT: Single crystals of (6-hydroxy-8-(2-hydroxyphenyl)-9-nitro-2,3,4,8-tetrahydro-1H-pyrido [1,2a]pyrimidin-7-yl)(1H-indol-3-yl)methanone. were grown by slow evaporation method and X-ray diffraction analysis reveals monoclinic $C 2 / c$ space group with unit cell dimensions of $a=34.9435(13) \AA, \quad b=8.8855(3) \AA$, $c=$ $15.0694(6) \AA$ and $\beta=95.591(1)^{\circ}$. The pyrimidine ring (N3-N4/C12-C15) makes dihedral angle of $68.08(9)^{\circ}$ with the phenyl ring (C18-C23). Crystal data were collected using BRUKER SMART APEX II CCD X-ray diffractometer. The structure was solved by direct method and refined on $\mathrm{F}^{2}$ by full-matrix least-squares procedure to the final $\mathrm{R}_{1}$ of 0.041 using SHELXL programs.

KEYWORDS: Indol, Pyridin, Crystal packing and crystal structure.

\section{INTRODUCTION}

Indole is an aromatic heterocyclic group, the parent of a large number of important compounds in nature with significant biological activity [1]. The indole ring system occurs in plants [2] for example, indole-3-acetic acid is a naturally occurring auxin that controls several plant growth activities [3, 4]. Indole derivatives exhibit antibacterial, antifungal [5], antitumor [6], antihepatitis B virus [7] and antiinflammatory [8] activities. They are also used as bioactive drugs [9] and have also been proven to display high aldose reductase inhibitory [10] and antimicrobial activities [11]. Indole derivatives are also found to possess hypertensive, muscle relaxant and antiviral activities [12]. Some of the indole alkaloids extracted from plants possess interesting cytotoxic and antiphrastic properties.

\section{EXPERIMENTAL}

\subsection{X-Ray Structure Determination}

Single crystal of the compound suitable for x-ray diffraction was obtained by slow evaporation method. Three dimensional intensity data were collected on a Bruker [13] SMART APEX CCD Diffractometer using graphite monochromatized Mo-K $\alpha$ radiation $(\lambda=$ $0.71073 \AA$ ) at Department of chemistry, IIT, Chennai, India. The structure was solved by direct methods and refined on $\mathrm{F}^{2}$ by full-matrix least-squares procedures using the SHELXL programs [14]. All the non-hydrogen atoms were refined using isotropic and later anisotropic thermal parameters. The hydrogen atoms were included in the structure factor calculation at idealized positions by using a riding model, but not refined. Images were created with ORTEP [15].The crystallographic data for the compound are listed in Table 1.

\subsection{Synthesis of the compound}

A dried, $10 \mathrm{~mL}$ round-bottomed flask was charged with 2-aminoprop-1-ene-1, 1, 3-tricarbonitrile 1 (1.0 mmol), 4-methylbezaldehyde 2 (1.1 mmol), and 2(nitromethylene) hexahydropyrimidine $3(1.0 \mathrm{mmol})$ in $\mathrm{EtOH}$ and $10 \mathrm{~mol} \%$ of piperidine was added to the reaction mixture and heated in an oil bath at reflux for the $5 \mathrm{~h}$. The consumption of the starting material was monitored by TLC. The precipitated solid was filtered and washed with ethanol (2-3 $\mathrm{mL})$, dried under vacuum to obtain pure product in excellent yield (79 $\%)$. Finally, the products were recrystallized from EtOH [16].

\section{RESULTS AND DISCUSSION}

In the title (6-hydroxy-8-(2-hydroxyphenyl)-9nitro-2,3,4,8-tetrahydro-1H-pyrido [1,2-a]pyrimidin-7yl)(1H-indol-3-yl) methanone compound with (methylsulfinyl methane(1:1), the pyrimidine ring (N3N4/C12-C15) inclained with the phenyl ring (C18-C23) system is $68.08(9)^{\circ}$. The dihedral angle between pyridine ring (N3, C10-C11/C15-C17) and phenyl ring (C1-C6) by $85.22(10)^{\circ}$. The oxygen atom deviate from phenyl ring and $1 \mathrm{H}$-pyrido [1,2-a]pyrimidin ring by 0.015 and $-0.409 \AA$ respectively. In the crystal, 
molecules are connected by $\mathrm{C}-\mathrm{H} . . . \mathrm{O}, \mathrm{O}-\mathrm{H} . . . \mathrm{O}$ and $\mathrm{N}-\mathrm{H}$...O hydrogen bonding interactions, which form centro symmetric patterns described by graph-set ring motif
$\mathrm{R}_{2}{ }^{2}$ (14). The packing view of the title compound is shown in fig. (2)

Table 1: 2D Crystal data and structure refinement of the titled compound

\begin{tabular}{|c|c|}
\hline Compound & Parameters \\
\hline Empirical formula & $\mathrm{C}_{24} \mathrm{H}_{26} \mathrm{~N}_{4} \mathrm{O}_{6} \mathrm{~S}_{1}$ \\
\hline Formula weight & 942.99 \\
\hline Temperature & $296(2) \mathrm{K}$ \\
\hline Wavelength & $0.71073 \AA$ \\
\hline Crystal system, space group & Monoclinic, C2/c \\
\hline Unit cell dimensions & $\begin{array}{ll}\mathrm{a}=34.9435(13) \AA & \text { alpha }=90^{\mathrm{o}} \\
\mathrm{b}=8.8855(3) \AA & \text { beta }=95.591^{\mathrm{o}} \\
\mathrm{c}=15.0694(6) \AA & \text { gamma }=90^{\circ}\end{array}$ \\
\hline Volume & $4656.6(3) \AA^{3}$ \\
\hline Z, Calculated density & $2,1.345 \mathrm{Mg} / \mathrm{m}^{3}$ \\
\hline$F(000)$ & 1976 \\
\hline Crystal size & $0.50 \times 0.40 \times 0.30 \mathrm{~mm}$ \\
\hline Theta range for data collection & 2.699 to $24.996 \mathrm{deg}$. \\
\hline Limiting indices & $\begin{array}{c}-41<=\mathrm{h}<=41,-10<=\mathrm{k}<=10 \\
-17<=\mathrm{l}<=17\end{array}$ \\
\hline Reflections collected / unique & $30682 / 4091[\mathrm{R}(\mathrm{int})=0.028]$ \\
\hline Completeness to theta $=24.996$ & $99.6 \%$ \\
\hline Max. and min. transmission & 0.959 and 0.933 \\
\hline Refinement method & Full-matrix least-squares on $\mathrm{F}^{2}$ \\
\hline Data / restraints / parameters & $4091 / 0$ / 324 \\
\hline Goodness-of-fit on $\mathrm{F}^{2}$ & 1.040 \\
\hline Final R indices [I $>2$ sigma(I)] & $\mathrm{R} 1=0.041, \mathrm{wR} 2=0.1182$ \\
\hline $\mathrm{R}$ indices (all data) & $\mathrm{R} 1=0.0492, \mathrm{wR} 2=0.1112$ \\
\hline
\end{tabular}

\section{D- Scheme Structure}<smiles>CS(=O)C1=C([N+](=O)[O-])N2CCCNC2=C([O-])C1c1ccccc1O</smiles>

Table 2: Hydrogen-bond geometry [Å]

\begin{tabular}{|c|c|c|c|c|}
\hline D-H...A & D-H & H...A & D...A & D-H...A \\
\hline N2-H2A...07i & 0.865 & $2.00(2)$ & $2.805(2)$ & 154 \\
\hline N3-H3A...05 ${ }^{\text {ii }}$ & 0.869 & $2.297(17)$ & $2.9799(18)$ & 135 \\
\hline O4-H4A...N1 ${ }^{\text {iii }}$ & 0.869 & $2.590(2)$ & $3.4018(1)$ & 155 \\
\hline C4-H4...03i ${ }^{v}$ & 0.93 & $2.520(4)$ & $3.237(3)$ & 134 \\
\hline
\end{tabular}

Symmetry code:
i) $2-x,-y, 2-z$
ii) $\mathrm{x}, 1-\mathrm{y}, 1 / 2+\mathrm{z}$
iii) $x,-y,-1 / 2+z$

Hemanathan et al., 


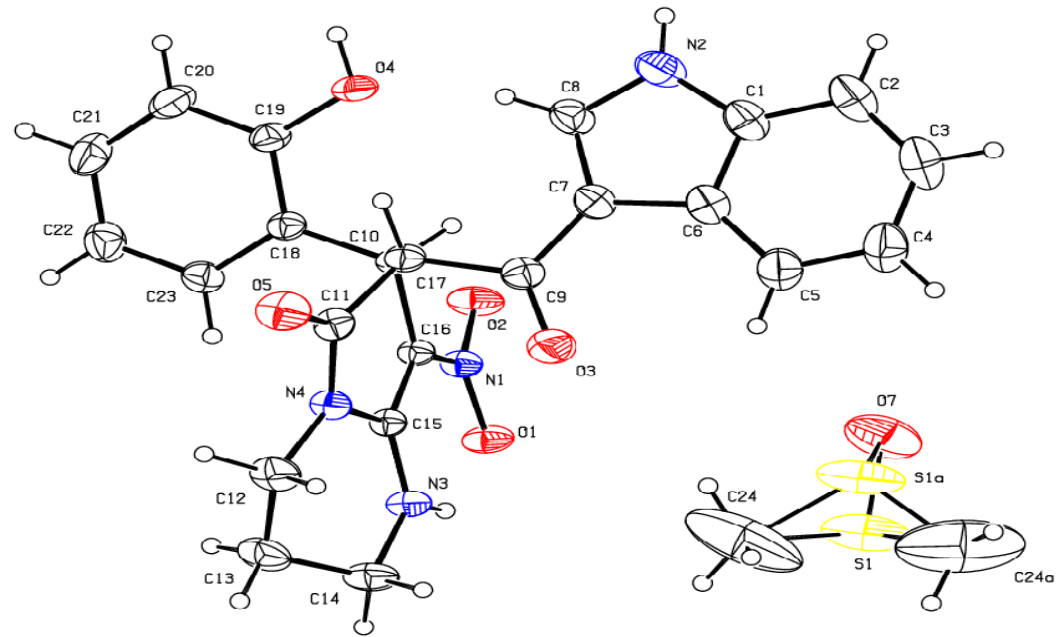

Figure 1 The molecular structure of the title compound with atom labeling. Displacement ellipsoids are drawn at the $30 \%$ probability level
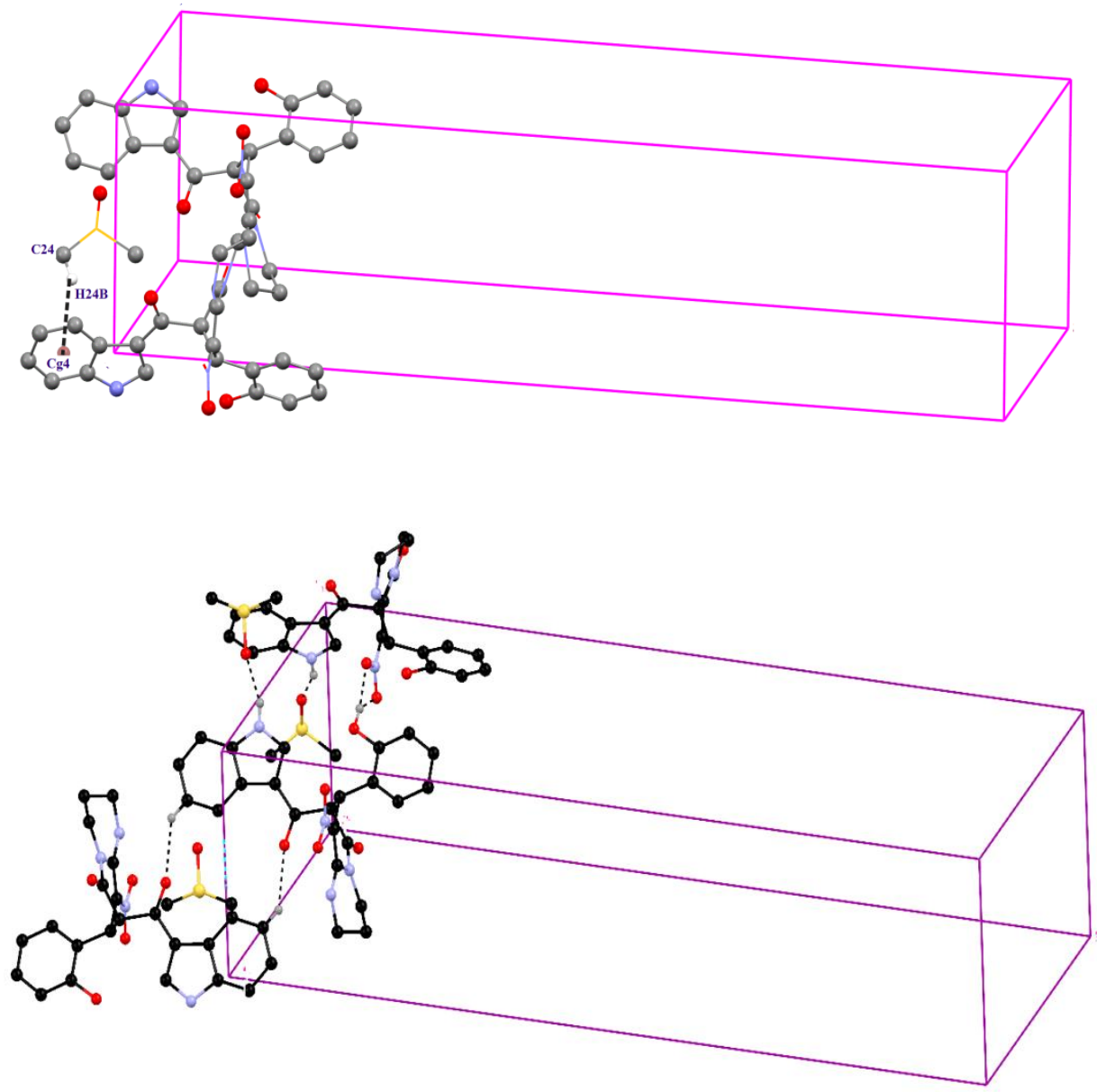

Hemanathan et al., 


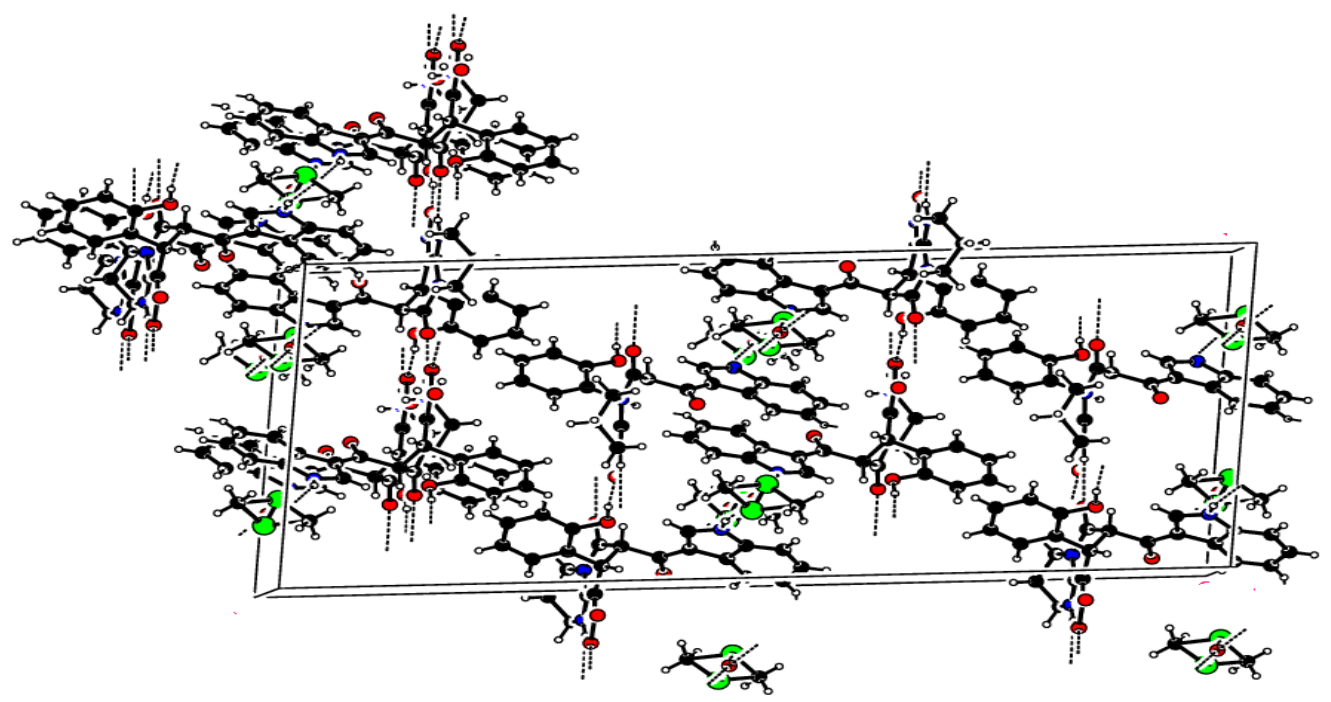

Figure 2 The crystal packing of the titled compound forming C-H...O interactions viewed along $b$ axis. The hydrogen bonds are shown as dashed lines (see Table 2 for details)

Table 3: Selected Some Bond lengths (Å)

\begin{tabular}{|c|c|c|c|}
\hline Atom & Length & Atom & Length \\
\hline C1-C2 & 1.390 & C9-O3 & 1.222 \\
\hline C1-C6 & 1.395 & C14-H14A & 0.970 \\
\hline C1-N2 & 1.382 & N1-01 & 1.285 \\
\hline C3-H4 & 0.930 & N1-O2 & 1.248 \\
\hline C6-C7 & 1.444 & O4-H4A & 0.870 \\
\hline C8-N2 & 1.337 & S1-C24 & 1.657 \\
\hline
\end{tabular}

Table 4: Selected Some Bond angles $(\stackrel{\mathrm{o}}{)}$

\begin{tabular}{|c|c|c|c|}
\hline Atom & Angle & Atom & Angle \\
\hline C1-C2-C3 & 117.12 & N4-C11-O5 & 120.36 \\
\hline C2-C1-C6 & 122.67 & C13-C12-N4 & 111.66 \\
\hline C2-C1-N2 & 129.59 & C18-C19-O4 & 116.70 \\
\hline C6-C1-N2 & 107.74 & C16-N1-O1 & 120.75 \\
\hline C3-C4-C5 & 121.50 & 07-S1-C24 & 107.33 \\
\hline C9-C10-C17 & 110.92 & S1-C24-H24A & 109.48 \\
\hline
\end{tabular}

\section{CONCLUSION}

The crystal structure analysis of a novel indol and pyridin compound was studied using x-ray diffraction method. In the compound, the crystal packing is stabilized by inter and intra molecular hydrogen bonds.

\section{ACKNOWLEDGMENT}

The authors thank the Department of Physics (SAIF), IIT, Chennai, India, for X-ray Intensity data collection. 


\section{REFERENCES}

[1]. Kaushik, N. K., Kaushik, N., Attri, P., Kumar, N., Kim, C. H., Verma, A. K. \& Choi, E.H., 2013. Biomedical Importance of Indoles, Molecules, 18, 6620-6662.

[2]. Nigovic, B., Antolic, S., Kojic-Prodic, B., Kiralj, R., Magnus, V. \& Salopek-Sondi, B., 2000. Correlation of structural and physico-chemical parameters with the bioactivity of alkylated derivatives of indole-3-acetic acid, a phytohormone (auxin), Acta Crystallographica Section B. 56, 94-111.

[3]. Moore, C. T., 1989. Biochemistry and Physiology of Plant Hormones, ch. 2, p. 33. New Delhi: Narosa Publishing House.

[4]. Fargasova, A., 1994. Bulletin of Environmental Contamination and Toxicology. 52, 706-711.

[5]. Singh, U. P., Sarma, B. K., Mishra, P. K. \& Ray, A. B., 2000. Antifungal activity of venenatine, an indole alkaloid isolated from Alstonia venenata. Folia Microbiologica. 45, 173-176.

[6]. Andreani, A., Granaiola, M., Leoni, A., Locatelli, A., Morigi, R., Rambaldi, M., Giorgi, G., Salvani, L. \& Garaliene, V., 2001. Synthesis and antitubercular activity of imidazo[2,1b]thiazoles. Anti-Cancer Drug Design. 16, 167174.

[7]. Chai, H., Zhao, C. \& Gong, P., 2006. Synthesis and in vitro anti-hepatitis $\mathrm{B}$ virus activities of some ethyl 6-bromo-5-hydroxy-1H-indole-3carboxylates. Bioorg. Medi. Chem. 14, 911- 917.

[8]. Rodriguez, J. G., Temprano, F., EstebanCalderon, C., Matrinez- Ripoll,M. \& GraciaBalanco, S., 1985. Conformational and molecular study of the 4-(2-carboxyethyl)1,2,3,4-tetrahydrocyclopent[b]indole.

Tetrahedron, 41, 3813-3823.
[9]. Stevenson, G. I., Smith, A. L., Lewis, S. G., Nedevelil, J. G., Patel, S., Marwood, R. \& Castro, J. L., 2000. 2-Aryl tryptamines: selective high-affinity antagonists for the h5-HT2A receptor. Bioorganic \& Medicinal Chemistry Letters. 10, 2697-2704.

[10]. Rajeswaran,W. G., Labroo, R. B., Cohen, L. A. \& King, M. M., 1999. Synthesis of 5-[(Indol-2-on3-yl)methyl]-2,2-dimethyl-1,3- dioxane-4,6diones and Spirocyclopropyloxindole Derivatives. Potential Aldose Reductase Inhibitors. Journal of Organic Chemistry. 64, 1369-1371.

[11]. Amal Raj, A ., Raghunathan, R., Sridevikumar, M. R. \& Raman, N., 2003. Synthesis, antimicrobial and antifungal activity of a new class of spiro pyrrolidines. Bioorganic \& Medicinal Chemistry. 11, 407-419.

[12]. Kolocouris, N., Foscolos, G. B., Kolocouris, A., Marakos, P., Pouli, N., Fytas, G., Ikeda, S. \& De Clercq, E., 1994. Synthesis and Antiviral Activity Evaluation of Some Aminoadamantane Derivatives. Journal of Medicinal Chemistry. 37, 2896- 2902.

[13]. Bruker (2008). APEX2, SADABS and SAINT. Bruker AXS Inc., Madison,Wisconsin, USA.

[14]. Sheldrick, G. M. (2008). A short history of SHELX. Acta Cryst. Section A. 64, 112-122.

[15]. Farrugia, L. J., 2012. Journal of Applied Crystallography. 45, 849-854.

[16]. Hemanathan, K., Raja, R., Kathivelan, D., Reddy, B, S, R, \& Sakthi Murugesan, K., 2015. Crystal structure analysis of (2'S,3'S,4'S)-3'-(4Chloro-2H-chromen-3-yl)-4'-(1H-indole-3carbonyl)-1'-methyl-2-oxospiro[indoline-3,2'pyrrolidine]-4'-carbonitrile.International Journal of Chem Tech Research. 8(6), 344-348.

All ( 2019 are reserved by International Journal of Advanced Science and Engineering. This Journal is licensed under a Creative Commons Attribution-Non Commercial-ShareAlike 3.0 Unported License.

Hemanathan et al., 